\title{
Novel pathogens beat food safety checks
}

Paris. Renewed calls were heard last week for regulatory systems to adapt to the threat of novel pathogens in the food supply after pies and gravy contaminated with the 0157:H7 strain of Escherichia coli killed five people in Scotland.

The outbreak of food poisoning - the worst in the country's history, infecting 260 people - is the latest in a series caused worldwide by the 0157:H7 strain since it was first detected in 1982. More than 600 people were affected in a US outbreak in 1987, while in Japan around 10,000 people were infected in an outbreak earlier this year that left 11 dead (see Nature 382, 567; 1996).

The bacterium produces powerful cytotoxins that can cause bloody diarrhoea (haemorrhagic colitis), haemolytic uraemic syndrome (HUS) and kidney failure. Mortality among those infected can be 5 to 10 per cent.

Clusters of such cases reported in the literature in the 1940s and 1950s in the United States and Europe closely resemble contemporary 0157:H7 outbreaks. This suggests the strain was present long before it was identified in 1982, says Bernard Rowe, head of the UK Public Health Laboratory Service's Laboratory of Enteric Pathogens.

The almost identical sequence of the toxin genes of the $E$. coli strain with those of the human pathogen Shigella dysenteria Type 1 is widely considered to show that 0157:H7 acquired the genes from Shigella through DNA swapping, says Mike Hudson, a specialist on the strain at the UK Centre for Applied Microbiology and Research at Porton Down in Wiltshire.

Hudson sees an increase in new food pathogens, including $E$. coli 0111 , another toxin-producing strain, and strains of Salmonella enterica resistant to temperatures that kill other bacteria during food processing. Antibiotic resistance has also become common. "We need to come to grips with how new pathogens appear in the food supply," says Paul Neal, an official at the food-borne diseases division of the US Center for Disease Control in Atlanta, Georgia.

Gene transfer in the wild is poorly understood, as is the impact of environmental changes on such processes, says Hudson. He speculates that the appearance of some new strains may be linked to changes in farming practices. Lack of understanding of the impact of changes in food production on microbial ecology means that "we could be storing up problems for ourselves", he says.

Some scientists are more sanguine, however. Christopher Higgins, professor of clinical biology at the University of Oxford, says he is not convinced that novel food pathogens are on the increase. Observations of so-called novel food poisoning agents

may be largely accounted for by improvements in the reporting of cases of illness, he argues. He says that changes such as the increasing use of frozen foods simply demand that appropriate food safety measures be introduced.

Many scientists argue, however, that the increasing industrialization of food production is a double-edged sword. They say that, although it has allowed major improvements

\section{IMAGE \\ UNAVAILABLE FOR COPYRIGHT REASONS}

Food for thought: passers-by ponder the shop window of the osed butchers where the latest $E$. coli outbreak originated.

in quality control, the increase in the scale of operations now means that "when something goes wrong it goes wrong in a big way".

Last week's food poisoning outbreak was centred on the town of Wishaw in Lanarkshire, southwest Scotland, and has been traced to pies and gravy produced by John Barr, a butcher and beef wholesaler who was recently nominated 'Scottish beef butcher of the year'. The British government immediately launched an inquiry into how the contamination occurred, and its implications for food safety procedures.

The frequency of outbreaks of $0157: \mathrm{H} 7$ throughout the world has steadily increased from 20 in 1983 to more than 800 last year. This is probably because people are now looking for it more carefully. But there is still evidence of "a slow but steady rise", according to Rowe.

He believes 0157:H7 will not reach the epidemic proportions of Salmonella enterica, which causes tens of thousands of cases annually in the United Kingdom alone. This is because the $E$. coli strain only occurs in around 1 per cent of cattle while Salmonella is widespread in poultry.

But Rowe acknowledges that the strain "is a very severe infection that has to be taken extremely seriously". Fewer than a dozen bacteria can be enough to cause illness. Most common food pathogens, such as Salmonella, cause illness only when they are present in food in thousands.

This low infectious dose means that control measures will need to eliminate 0157:H7 almost completely from the food chain. This makes it "the ultimate test for the regulatory system", says Hugh Pennington of Aberdeen University, the chairman of the UK inquiry panel. "It is testing the regulatory system and the system is failing."

"The things we are discovering about 0157:H7 are demanding us to rethink some of the fundamentals by which we control food safety," adds Catherine Reynolds, spokeswoman for the UK Institute of Food Research. The strain can survive acid conditions, for example, by becoming dormant until conditions become more suitable.

- There is an urgent need for better $\sum_{i}^{\infty}$ understanding of the survival mecha$\sum$ nisms of bacteria under non-growing 产 conditions, says Reynolds.

The ability of $0157: \mathrm{H} 7$ to survive acid environments increases the risk of foods such as mayonnaise and salami becoming infected.

The main reservoir of $0157: \mathrm{H} 7$ is the gut of cattle. Its main route into the food chain is through contamination of meat by intestinal contents and faeces in the abattoir. The organism cannot be eradicated from cattle as it is now part of their normal flora says Rowe. "We have got to tighten up the food chain absolutely everywhere".

Most outbreaks have been linked to hamburgers or minced meat products. Mincing results in bacteria being transferred to the interior of such products where they can survive all but thorough cooking. With steaks and other meat cuts, in contrast, bacteria are restricted to the outer surface where they are readily killed by cooking. But infections have also occurred through milk, fruit juices, water and person-to-person contact. "We are recognizing a growing role for fruits and vegetables in outbreaks in the United States over the past two years," says Neal.

The United States has already tightened procedures in response to the outbreak in 1987, introducing a 'pathogen reduction programme' throughout the meat industry. This represents a major shift in quality control procedures, according to Neal, away from random inspection of individual carcasses to monitoring general microbial levels throughout the chain and taking steps to reduce them. "We are trying to determine whether the process is minimizing contamination at every step," says Neal. He adds that, by reducing overall microbial levels, the risk of 0157:H7 contamination should also fall.

The appearance of the strain has strengthened calls from consumer associations in the wake of the 'mad cow' crisis in Europe for systems that allow food products to be traced all along the food chain "from the farm to the table".

Tracking the origin of foods in outbreaks of food poisoning is notoriously difficult. "We can identify the food fairly easily, but working back to the animals is horrendously difficult, and the track often runs cold," says Pennington.

Declan Butler 